\title{
Gamma Knife surgery for craniopharyngioma: report on a 20-year experience
}

\author{
Clinical article
}

\author{
Cheng-Chia Lee, M.D., ${ }^{1-3}$ Huai-Che Yang, M.D., ${ }^{1,3}$ Ching-Jen Chen, M.D., ${ }^{6}$ \\ Yi-Chieh Hung, M.D., ${ }^{1,3}$ Hsiu-Mei Wu, M.D., ${ }^{3,4}$ Cheng-Ying Shiau, M.D., ${ }^{3,5}$ \\ Wan-Yuo Guo, M.D., Ph.D., ${ }^{3,4}$ David Hung-Chi Pan, M.D., ${ }^{1,3}$ Wen-Yuh Chung, M.D., ${ }^{1,3}$ \\ AND KANG-DU LIU, M.D. ${ }^{1,3}$
}

\begin{abstract}
${ }^{1}$ Department of Neurosurgery, Neurological Institute, Taipei Veterans General Hospital, Taipei; ${ }^{2}$ Department of Surgery, Hsinchu Branch, Taipei Veterans General Hospital, Hsinchu; ${ }^{3}$ School of Medicine, National Yang-Ming University, Taipei; ${ }^{4}$ Department of Radiology and ${ }^{5}$ Cancer Center, Taipei Veterans General Hospital, Taipei, Taiwan; and ${ }^{6}$ Department of Neurological Surgery, University of Virginia Health System, Charlottesville, Virginia
\end{abstract}

\begin{abstract}
Object. Although craniopharyngiomas are benign intracranial tumors, their high recurrence rates and intimate associations with surrounding neurovascular structures make gross tumor resection challenging. Stereotactic radiosurgery has been introduced as a valuable adjuvant therapy for recurrent or residual craniopharyngiomas. However, studies with large patient populations documenting long-term survival and progression-free survival rates are rare in the literature. The current study aims to report the long-term radiosurgical results and to define the prognostic factors in a large cohort of patients with a craniopharyngioma.

Methods. A total of 137 consecutive patients who underwent 162 sessions of Gamma Knife surgery (GKS) treatments at the Taipei Veterans General Hospital between 1993 and 2012 were analyzed. The patients' median age was 30.1 years (range 1.5-84.9 years), and the median tumor volume was $5.5 \mathrm{ml}$ (range 0.2-28.4 ml). There were 23 solid (16.8\%), 23 cystic (16.8\%), and 91 mixed solid and cystic (66.4\%) craniopharyngiomas. GKS was indicated for residual or recurrent craniopharyngiomas. The median radiation dose was $12 \mathrm{~Gy}$ (range 9.5-16.0 Gy) at a median isodose line of $55 \%$ (range $50 \%-78 \%$ ).

Results. At a median imaging follow-up of 45.7 months after GKS, the rates of tumor control were $72.7 \%$, $73.9 \%$, and $66.3 \%$ for the solid, cystic, and mixed tumors, respectively. The actuarial progression-free survival rates plotted by the Kaplan-Meier method were $70.0 \%$ and $43.8 \%$ at 5 and 10 years after radiosurgery, respectively. After repeated GKS, the actuarial progression-free survival rates were increased to $77.3 \%$ and $61.2 \%$ at 5 and 10 years, respectively. The overall survival rates were $91.5 \%$ and $83.9 \%$ at the 5- and 10 -year follow-ups, respectively. Successful GKS treatment can be predicted by tumor volume $(\mathrm{p}=0.011)$. Among the 137 patients who had clinical follow-up, new-onset or worsened pituitary deficiencies were detected in 11 patients $(8.0 \%)$. Two patients without tumor growth had a worsened visual field, and 1 patient had a new onset of third cranial nerve palsy.

Conclusions. The current study suggests that GKS is a relatively safe modality for the treatment of recurrent or residual craniopharyngiomas, and it is associated with improved tumor control and reduced in-field recurrence rates. Acceptable rates of complications occurred.
\end{abstract}

(http://thejns.org/doi/abs/10.3171/2014.8.GKS141411)

KEY WoRds $\bullet \quad$ craniopharyngioma $\bullet \quad$ Gamma Knife surgery $\bullet$
progression-free survival $\bullet \quad$ stereotactic radiosurgery $\bullet \quad$ survival

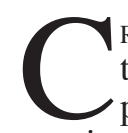

RANIOPHARYNGIOMAS are benign parasellar tumors that arise from residual epithelial cells of Rathke's pouch. These tumors are characterized by a propensity to involve and densely adhere to surrounding vital neurovascular structures. ${ }^{21,25}$ Although the mainstay therapeutic approach is surgical gross-total resection (GTR),

Abbreviations used in this paper: GKS = Gamma Knife surgery; $\mathrm{GTR}=$ gross-total resection; $\mathrm{RT}=$ radiotherapy; $\mathrm{SRS}=$ stereotactic radiosurgery. intimate association of the tumor with the surrounding neurovascular structures can make resection challenging. Despite improvements in surgical outcomes with advances in microsurgical and endoscopic techniques, significant operative morbidity and mortality rates continue to pose formidable challenges to long-term remission from craniopharyngiomas. ${ }^{1,5,17,24}$ Therefore, adjuvant therapies, such as radiation therapy, have been considered since as early as $1904 .^{25}$

Radiotherapy (RT) has emerged as a valuable ad- 
juvant treatment modality for recurrent or residual craniopharyngiomas. Several radiotherapeutic modalities, including conventional external-beam radiation therapy, intensity-modulated radiation therapy, single-fraction stereotactic radiosurgery (SRS) (e.g., Gamma Knife surgery [GKS]), fractionated stereotactic RT, and proton beam RT, have been used over the past decades and offer reasonable rates of tumor control. With advances in neuroimaging and RT modalities, dose delivery is more accurate and focused, resulting in decreased long-term complication rates over time. In this study, we reviewed a series of cases in which patients with craniopharyngioma were all treated by GKS. The long-term efficacy and safety of GKS were evaluated. Complications and prognostic factors were also analyzed. The goal of this report is to define the role of GKS in the current treatment of patients with craniopharyngioma.

\section{Methods}

A consecutive series of 137 patients with a craniopharyngioma underwent GKS at our institution between March 1993 and December 2012. Clinical data, including patient demographics, outcome of resection, adjuvant radiosurgical parameters, and imaging results, were retrospectively reviewed from an institutional review boardapproved database.

The clinical survey of the patients with a craniopharyngioma included a meticulous neurological examination, a comprehensive hormone study, and ophthalmological evaluations, including formal visual acuity and visual field testing. Systemic endocrine studies, including obtaining the growth hormone, insulin-like growth factor-1, adrenocorticotropic hormone, serum cortisol, prolactin, triiodothyronine, thyroxine, free thyroxine, thyroxin-stimulating hormone, luteinizing hormone, follicle-stimulating hormone, and estrogen (for female patients) or testosterone (for male patients) levels, were performed. Comprehensive hormone studies were performed for patients with a craniopharyngioma before and after their GKS.

Neuroimaging studies consisted of CT scans and MR images with and without contrast using thin slices and volume acquisition through the region of the sella turcica; an estimate of the volume of each tumor was established by MR volumetry. The sum of the areas was multiplied by the thickness of the MRI section, thus yielding the total tumor volume. ${ }^{39}$

GKS is intended to treat residual or recurrent craniopharyngiomas. In patients with mixed-type tumors, especially those with large cystic lesions adjacent to a solid nodular component, GKS has been reserved largely for treating only the solid portion in conjunction with the instillation of radioisotopes for the cystic portion. In patients with a purely cystic craniopharyngioma, aspiration immediately before GKS was used for better tumor control.

\section{Gamma Knife Technique}

At Taipei Veterans General Hospital, a Leksell frame was placed for all adult patients under local anesthesia. Pediatric patients younger than 14 years were given general anesthesia for frame placement, which was main- tained throughout the GKS procedure. Stereotactic MRI was then performed for treatment planning. If a patient could not tolerate MRI due to incompatible implants, a CT scan was used to define the target. For craniopharyngiomas, the goal of GKS dose planning was to cover the solid component of the tumor with 1 or more isocenters while limiting irradiation of the surrounding normal structure as much as possible, especially radiation-sensitive tissue such as the optic apparatus, hypothalamus, and brainstem. Craniopharyngiomas in close proximity to the optic apparatus were treated with relatively lower doses, such that the maximum dose to the visual pathway structures was less than $12 \mathrm{~Gy}$. Cystic components were treated with stereotactic aspiration followed by radiosurgery on the same day or within several days.

\section{Imaging and Clinical Follow-Up}

After GKS, all the patients underwent clinical and endocrinological evaluations at an average of 6-month intervals. Tumor growth was defined as an increase of at least $10 \%$ in volume. Tumor shrinkage was defined as at least a $10 \%$ decrease in volume. A tumor that was within $10 \%$ of its original volume was defined as stable. In this study, good tumor control was defined as stability/reduction in solid tumor volume regardless of outfield tumor growth and/or cystic enlargement. Poor tumor control included growth in solid tumor volume irrespective of initial or delayed enlargement. Postradiosurgery visual field deficits, hypopituitarism, cranial nerve dysfunction, and diabetes insipidus were characterized as improved, stable, or worsened.

\section{Statistical Analysis}

Data are presented as the median or mean and range for continuous variables and as frequencies and percentages for categorical variables. Statistical analyses of the categorical variables were carried out using the chisquare test, Fisher's exact test, and the Mantel-Haenszel test for linear association, as appropriate. Statistics of the means were determined using the unpaired Student t-test, with and without equal variance (Levene test), as necessary, and the Wilcoxon rank-sum test when the variables were not normally distributed. Kaplan-Meier curves were plotted for progression-free survival and overall survival rates from the time of GKS, last follow-up, and treatment failure, if any.

The logistic regression model was used to analyze the prognostic factors of hypopituitarism. Significant variables and interaction expansion covariates were further assessed in both logistic multivariate analyses, as deemed relevant. Probability values $<0.05$ were considered statistically significant. Statistical analyses were performed using IBM SPSS (version 20.0).

\section{Results}

\section{Patient Demographics}

In this series, the median age of the patients at diagnosis was 27.1 years (range $0.6-84.8$ years), and the median age of the patients at GKS was 30.1 years (range 1.5-84.9 
years). The cohort consisted of 81 (59\%) female patients. Before GKS, a combination of typical clinical features of craniopharyngiomas was found: visual field deficits $(\mathrm{n}=$ 127 [92.7\%]), pituitary dysfunction $(n=118$ [86.1\%]), diabetes insipidus ( $\mathrm{n}=85[62.0 \%])$, other hypothalamic dysfunction $(\mathrm{n}=32$ [23.4\%]), and other cranial nerve deficits ( $\mathrm{n}=10$ [7.3\%]). The median tumor volume was $5.5 \mathrm{ml}$ (range 0.8-28.4 ml). A pure solid craniopharyngioma was present in $23(16.8 \%)$ patients, a purely cystic craniopharyngioma in $23(16.8 \%)$ patients, and a mixed-type craniopharyngioma in $91(66.4 \%)$ patients. In terms of tumor location, $126(92.0 \%)$ patients had a craniopharyngioma extending to the suprasellar region, $24(17.5 \%)$ tumors extended into the third ventricle, $31(22.6 \%)$ had cavernous sinus extension, and 4 (2.9\%) extended to the retrosellar region (Table 1).

Resection such as craniotomy or transsphenoidal surgery was suggested as the first-line treatment for 94 patients $(68.6 \%)$. For patients who had a purely cystic craniopharyngioma, biopsy ( $\mathrm{n}=3[2.2 \%]$ ) and aspiration $(n=28$ [20.4\%]) were performed. An alternative was the placement of Ommaya reservoirs for the intermittent aspiration of cysts that could not be completely resected $(\mathrm{n}=21[15.3 \%])$. When repeated cyst aspirations were deemed inadvisable, intralesional RT or chemotherapy was used ( $\mathrm{n}=5[3.6 \%])$. Minimal excision combined with intermittent intralesional bleomycin through an Ommaya reservoir was used for children with cystic craniopharyngiomas $(\mathrm{n}=3)$. Another alternative for patients with a solitary or multicystic tumor was intracavitary irradiation via stereotactically applied radioisotopes $(n=2)$. Beta-emitting isotopes such as yttrium-90, rhenium-196, and phosphorus-32 were preferred because of the limited penetration of the emitted energy and the relative ease of handling (Table 1).

\section{Treatment Parameters}

A median margin dose of 12.0 Gy (range 9.5-16.0 Gy) was delivered to a median isodose line of 55\% (50\%$78 \%$ ). The median maximum dose was $21.8 \mathrm{~Gy}$ (range 15.4-32.0 Gy), and the median mean dose was 16.2 Gy (range 12.9-21.4 Gy) (Table 2).

\section{Tumor Control}

Nine $(6.6 \%)$ of the 137 patients were lost to followup, and their post-GKS images were not available. The median neuroimaging follow-up time of the other $128 \mathrm{pa}-$ tients was 45.7 months (range 6-226 months). Follow-up times of at least 2, 4, and 6 years were obtained for 87 , 56 , and 34 patients, respectively. At the last follow-up, a decrease in tumor volume was observed in 69 patients (53.9\%), and 2 patients (1.6\%) were in stable condition after GKS (Table 3).

However, $21(16.4 \%)$ of 128 patients had tumors that had enlarged despite GKS, 19 (14.8\%) patients had initial tumor shrinkage followed by delayed growth, $6(4.7 \%)$ patients had new lesions that were outside the previous GKS field (outfield recurrence), and 11 (8.6\%) patients had only cyst enlargement without tumor growth. A discrepancy between tumor and cyst growth, which was treated by simple aspiration or bleomycin injection (Table 3), sometimes occurred after GKS. The detailed numbers and percentages of tumor response in the 3 groups of patients are listed in Table 4 to compare the efficacy of GKS with regard to different features of their craniopharyngiomas. Good tumor control was achieved in $72.7 \%, 73.9 \%$, and $66.3 \%$ for patients with purely solid tumors, purely cystic tumors, and mixed solid and cystic tumors, respectively (Table 5).

The actuarial progression-free survival rates plotted by the Kaplan-Meier method were $70.0 \%$ and $43.8 \%$ at 5 and 10 years after radiosurgery, respectively (Fig. 1). The overall survival rates in this group of patients were $91.5 \%$ and $83.9 \%$ at the 5- and 10-year follow-ups, respectively (Fig. 2). Images from 2 patients with a craniopharyngioma who had excellent tumor response are shown in Figs. 3 and 4.

Prognostic factors were analyzed using univariate and multivariate analysis by logistic regression (Table 6). A smaller tumor volume before GKS was associated with successful GKS treatment ( $p=0.050$ [univariate analysis] and 0.011 [multivariate analysis]) (Fig. 5). Other factors such as age, sex, margin dose, maximum dose, mean dose, tumor extension, previous visual field deficits, pathological classification, and the extent of resection were not associated with the tumor control outcome (Table 6).

\section{Neurological and Endocrinological Results}

The median neurological and endocrinological follow-up time was 52.6 months (range 6-226 months). Of the 137 patients, $127(92.7 \%)$ were found to have visual field deficits before GKS, and 13 of them $(9.5 \%)$ showed subjective and objective improvement at the last followup; 118 patients $(86.1 \%)$ had preexisting hypopituitarism, and none discontinued their hormone replacement treatment after GKS. At the last follow-up, only 1 of 10 patients with cranial nerve dysfunction had shown improvement. Three patients with diabetes insipidus who needed medications before radiosurgery were able to discontinue their medications, and their quality of life was much improved (Table 7).

Most patients had stable neurological results, but a few had neurological and endocrinological deterioration, mostly related to tumor growth. For example, visual field progression was present in 28 patients, 2 of whom were without tumor growth. Seven patients suffered cranial nerve palsy, 1 of whom had no tumor recurrence. Neurological deficits without tumor growth may be results of radiation injury and, thus, were considered to be complications of GKS. The mortality rate in this series was $8.8 \%$ (Table 7).

\section{Complications}

Hypopituitarism. A pre-GKS loss of 1 or more pituitary axes was present in 118 patients $(86.1 \%)$. New-onset or worsened pituitary deficiencies were detected in $8.0 \%$ $(\mathrm{n}=11)$ of the patients and were seen in the thyroid axis $(\mathrm{n}=8)$, cortisol axis $(\mathrm{n}=8)$, growth hormone axis $(\mathrm{n}=$ $3)$, and gonadotroph axis $(n=2)$. Two patients developed panhypopituitarism after GKS. The median time to de- 
TABLE 1: Characteristics of 137 patients with a craniopharyngioma who underwent GKS*

\begin{tabular}{|c|c|c|c|}
\hline Characteristic & Value & Range & $\%$ \\
\hline \multicolumn{4}{|l|}{ age at diagnosis (yrs) } \\
\hline median & 27.1 & $0.6-84.8$ & \\
\hline mean & 28.6 & & \\
\hline \multicolumn{4}{|l|}{ age at GKS (yrs) } \\
\hline median & 30.1 & $1.5-84.9$ & \\
\hline mean & 30.3 & & \\
\hline sex (F/M ratio) & $81: 56$ & & \\
\hline median tumor vol (ml) & 5.5 & $0.2-28.4$ & \\
\hline \multicolumn{4}{|l|}{ classification } \\
\hline solid & 23 & & 16.8 \\
\hline cystic & 23 & & 16.8 \\
\hline mixed & 91 & & 66.4 \\
\hline no. of tumors w/ suprasellar extension & 126 & & 92.0 \\
\hline no. of tumors w/ 3rd ventricle extension & 24 & & 17.5 \\
\hline no. of tumors w/ cavernous sinus invasion & 31 & & 22.6 \\
\hline no. of tumors w/ retrosellar extension & 4 & & 2.9 \\
\hline no. of patients w/ previous resections & 94 & & 68.6 \\
\hline 5 resections & 1 & 0 GTR† & \\
\hline 4 resections & 3 & $0 \mathrm{GTR} \dagger$ & \\
\hline 3 resections & 4 & 0 GTR† & \\
\hline 2 resections & 20 & 2 GTR $\dagger$ & \\
\hline 1 resection & 66 & 4 GTR† & \\
\hline no. of patients w/ previous biopsy & 3 & & 2.2 \\
\hline no. of patients w/ previous cyst aspiration & 28 & & 20.4 \\
\hline no. of patients w/ previous Ommaya reservoir placement & 21 & & 15.3 \\
\hline no. of patients w/ previous intracavity $\mathrm{Tx}$ (RT or chemo) & 5 & & 3.6 \\
\hline no. of patients w/ previous VP shunt placement & 88 & & 64.2 \\
\hline no. of patients w/ previous RT & 10 & & 7.3 \\
\hline no. of patients w/ previous chemo & 6 & & 4.4 \\
\hline pre-GKS visual field deficits & 127 & & 92.7 \\
\hline pre-GKS hypopituitarism & 118 & & 86.1 \\
\hline pre-GKS diabetes insipidus & 85 & & 62.0 \\
\hline pre-GKS hypothalamic dysfunction & 32 & & 23.4 \\
\hline pre-GKS CN deficits & 10 & & 7.3 \\
\hline
\end{tabular}

* chemo = chemotherapy; $\mathrm{CN}=$ cranial nerve; TV = tumor volume; $\mathrm{Tx}=$ treatment; $\mathrm{VP}=$ ventriculoperitoneal.

$\dagger$ No. of patients with GTR of tumor. Only 6 patients had GTR, in most of whom the GTR was achieved in the first or second resection.

velopment of a new pituitary hormone deficiency was 37 months (Table 8).

Other Complications. Two patients had adverse radiation effects that appeared on MRI studies 18 months after GKS; however, these patients were asymptomatic. There were 2 patients without tumor growth who suffered worsened visual field deficits, and 1 patient without tumor growth who developed new-onset third cranial nerve palsy. Fifteen patients (10.9\%), together with the patients with new-onset hypopituitarism, may have suffered radiation injury and, hence, were included as those who experienced complications of GKS (Table 8).

TABLE 2: Treatment parameters of the patients with a craniopharyngioma

\begin{tabular}{lcc}
\hline \multicolumn{1}{c}{ Parameter } & Median Value & Range \\
\hline radiation vol $(\mathrm{ml})$ & 7.2 & $0.5-34.0$ \\
margin dose $(\mathrm{Gy})$ & 12.0 & $9.5-16.0$ \\
maximum dose $(\mathrm{Gy})$ & 21.8 & $15.4-32.0$ \\
mean dose $(\mathrm{Gy})$ & 16.2 & $12.9-21.4$ \\
isodose level $(\%)$ & 55.0 & $50-78$ \\
no. of isocenters & 12 & $2-29$ \\
\hline
\end{tabular}


TABLE 3: Imaging outcomes of 128 patients with a craniopharyngioma after GKS*

\begin{tabular}{lccc}
\hline \multicolumn{1}{c}{ Tumor Vol Change } & No. of Patients & Ratio $(\%)$ & Additional Management \\
\hline shrinkage & 69 & 53.9 & \\
stable & 2 & 1.6 & \\
growth & 21 & 16.4 & 16 resections, 5 RT, 4 re-GKS, 5 observations \\
initial shrinkage/regrowth & 19 & 14.8 & 11 re-GKS, 7 resections, 2 RT, no observations \\
new lesion development & 6 & 4.7 & 5 re-GKS, 1 resection \& RT, no observations \\
cyst growth only & 11 & 8.6 & 11 aspirations, 6 Ommaya reservoirs for aspiration, 5 re-GKS, \\
& & 4 RT, 1 bleomycin, 2 resections \\
\hline
\end{tabular}

* Imaging data were available for only 128 patients in this 137-patient series.

\section{Additional Management After GKS}

Among patients with tumor growth $(\mathrm{n}=21)$ after GKS, 16 underwent resection and 5 were observed. Among the 16 patients who underwent resection, 5 received adjuvant RT and 4 received repeated GKS. Of the patients who had initial tumor shrinkage followed by delayed regrowth $(\mathrm{n}=19), 11$ underwent repeated GKS, 7 underwent resection, 2 underwent RT. Observation was not an option of management. Of the patients with an outfield recurrence $(n=6), 5$ received repeated GKS and 1 underwent craniotomy plus RT. For these patients, a waitand-see approach was not an option. All the patients with isolated cyst enlargement underwent aspiration, and 6 of them received an Ommaya reservoir implantation. After aspiration of the cyst, 5 patients received repeated GKS, 4 received conventional RT, and 1 patient began bleomycin injection. A craniotomy for cyst removal was performed in 2 cases (Table 3). In each of the patients who required resection, histological results indicated either an adamantinomatous or a papillary subtype of craniopharyngioma. No changes in diagnosis were made.

The tumor control rates in the patients with a craniopharyngioma after a single GKS were $75 \%$ at 3 years, $70 \%$ at 5 years, $54 \%$ at 8 years, and $44 \%$ at 10 years GKS (Fig. $6)$. The rates were higher with repeated GKS: $82 \%$ at 3 years, $77 \%$ at 5 years, $64 \%$ at 8 years, and $61 \%$ at 10 years. The difference was statistically significant $(\mathrm{p}=0.003)$.

\section{Discussion}

Surgical results for craniopharyngiomas have shown

TABLE 4: Imaging outcomes of 128 patients with a craniopharyngioma after GKS based on features of the tumor*

\begin{tabular}{lrrrr}
\hline \multirow{2}{*}{ Tumor Vol Change } & \multicolumn{3}{c}{ Tumor Type, No. } & \\
\cline { 2 - 4 } & Solid & Cystic & Mixed & Total No. \\
\hline shrinkage & 12 & 14 & 43 & 69 \\
stable & 1 & 1 & 0 & 2 \\
growth & 2 & 4 & 15 & 21 \\
initial shrinkage/regrowth & 4 & 2 & 13 & 19 \\
new lesion development & 3 & 0 & 3 & 6 \\
cyst growth only & 0 & 2 & 9 & 11 \\
\hline
\end{tabular}

* Imaging data were available for only 128 patients in this 137-patient series. that a complete resection rate of $45 \%-90 \%$ can be achieved, ${ }^{6,27,37,38,41,48}$ with a reported 5-year tumor control rate of 70\%-90\%.11,15,41 Similar tumor control and recurrence rates were achieved for patients who underwent transsphenoidal surgery. ${ }^{6,11}$ However, recurrence rates of up to $85 \%$ were observed for partially resected craniopharyngiomas. ${ }^{11,37,38,41,48}$ Mortality rates in patients with a partially resected craniopharyngioma have ranged from $0 \%$ to $4 \% .{ }^{11,37,41}$ In contrast, a dramatic increase in mortality rates to $10 \%-17 \%$ was demonstrated when aggressive resection was attempted to achieve total resection. ${ }^{45}$ Its associated morbidity (e.g., pituitary dysfunction, hypothalamic dysfunction, and visual and neurocognitive deficits) rate has ranged from $20 \%$ to $80 \% .^{11,15,16,41}$

Gamma Knife surgery results for patients with a craniopharyngioma have been reported in 14 previously published reports. . $^{-4,7,8,18,22,23,30,32,34,40,44,46,47}$ In 4 reports with long-term follow-up periods, the 5-year progressionfree survival rates were $52 \%-68 \%$, with 5-year overall survival rates of $86 \%-97 \%$ (Table 9). In a series of 37 patients ${ }^{44}$ who underwent GKS for a craniopharyngioma, the 5-year overall survival and in-field progressionfree survival rates were $75.6 \%$ and $67 \%$, respectively. Hasegawa et al. ${ }^{13}$ reported 5- and 10-year progressionfree survival rates of $62 \%$ and $52 \%$, respectively, in 100 patients with a craniopharyngioma, Niranjan et al. ${ }^{32}$ reported a $97.5 \%$ overall survival rate 5 years after GKS and a 91.6\% 5-year progression-free survival rate among 46 patients with long-term follow-up (mean 62.2 months). A possible explanation for the discrepancies in overall survival and progression-free survival rates among the different craniopharyngioma radiosurgical series may be the relatively smaller number of patients and shorter follow-up periods in these studies compared with those in reports from conventional RT series.

In the Xu et al. series, ${ }^{44}$ prognostic factors associated with the in-field progression-free survival rate were an absence of visual field deficits before GKS, a solid tumor volume of less than $1.6 \mathrm{ml}$, and a margin dose greater than 14.5 Gy The magnitude of the margin dose depends considerably on tumor volume and its proximity to critical structures. ${ }^{9,13}$ Higher margin doses seem to be associated with prolonged progression-free survival. Additional factors associated with a favorable response to GKS, as shown in previous reports, were noncystic tumor composition, fewer previous interventions, and lower tumor volume. For patients with significant tumor recurrence, 
TABLE 5: Imaging outcomes of 128 patients with a craniopharyngioma after GKS based on features of the tumor*

\begin{tabular}{ccccc}
\hline & \multicolumn{3}{c}{ Tumor Type, No. } & Total \\
\cline { 2 - 4 } Tumor Control & Solid $(\mathrm{n}=22)$ & Cystic $(\mathrm{n}=23)$ & Mixed $(\mathrm{n}=83)$ & $88(68.8)$ \\
\hline good $(\%) \dagger$ & $16(72.7)$ & $17(73.9)$ & $55(66.3)$ & $40(31.3)$ \\
\hline poor $(\%) \ddagger$ & $6(27.3)$ & $6(26.1)$ & $28(33.7)$ & 40 \\
\hline
\end{tabular}

* The $2 \times 3$ chi-square test showed no differences between tumor control and tumor types $(p=0.710)$.

$\dagger$ Good tumor control included shrinkage, stability, new lesion development, and cyst growth, forming a good tumor control group.

$\ddagger$ Poor tumor control included growth, initial shrinkage, and regrowth, forming a poor tumor control group.

cytoreductive surgery may be considered before treatment with GKS. ${ }^{8,44}$

With repeated GKS, tumor control rates can be improved by $7 \%, 7 \%, 10 \%$, and $17 \%$ at the $3-, 5-, 8-$, and 10-year follow-ups, respectively (Fig. 5). We believe that repeated radiosurgery plays an important role in preventing tumor enlargement, especially for small tumors distant from the optic apparatus.

\section{Cyst Development and Enlargement During Radiation Therapy}

The cystic component of a craniopharyngioma commonly presents a problem for radiation therapy and radiosurgery. Cyst reaccumulation is not equivalent to tumor recurrence, and shrinkage of the tumor's solid component is not always accompanied by cyst regression. The solid component of the tumor can usually be controlled by radiation. In contrast, the cystic component may require surgical decompression. Tumor growth and cyst enlargement can be independent. On the basis of this principle, several approaches can be taken in the management of patients with a cystic craniopharyngioma either at initial presentation or at recurrence. Of these approaches, the following treatments are commonly used to decrease cyst size: intermittent aspiration by stereotactic puncture or placement of an Ommaya reservoir, sclerosis of the cyst

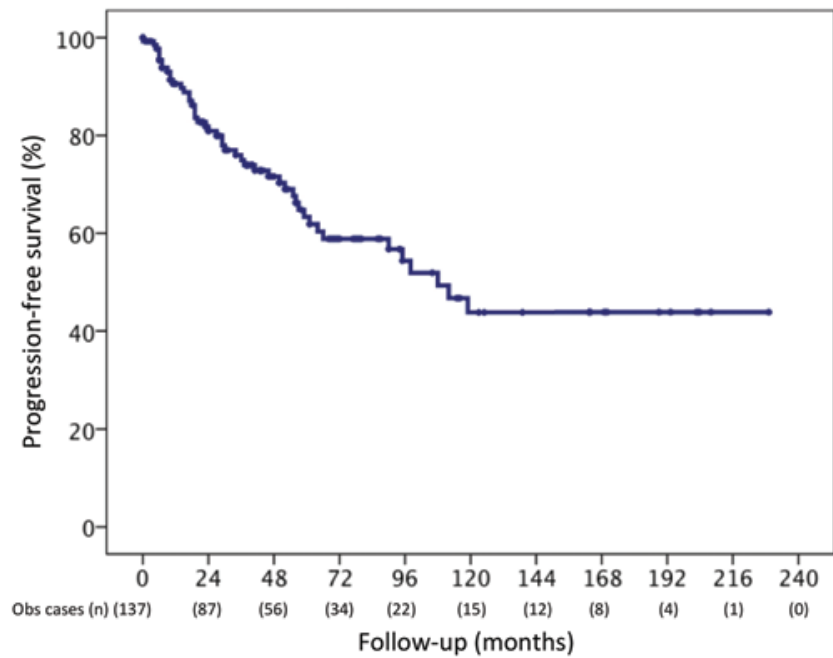

Fig. 1. Kaplan-Meier progression-free survival curve for patients with a residual or recurrent craniopharyngioma after GKS. The progression-free survival rates were $70.0 \%$ and $43.8 \%$ at the 5 - and 10 -year follow-ups, respectively. Obs = observed. wall by chemotherapeutic drugs, and internal irradiation (i.e., brachytherapy) with implanted radioisotopes.

Percutaneous aspiration of cyst contents has been used to alleviate cyst-related symptoms, and intermittent aspiration may be recommended for patients who are poor surgical candidates. An alternative is the placement of an Ommaya reservoir for the intermittent aspiration of a cyst that cannot be completely resected. Recently, several case reports indicated that stereotactic cyst aspiration in conjunction with same-day SRS achieved good tumor control (Fig. 3). ${ }^{14,26,33}$

\section{Debates}

Although the beneficial effect of radiation in the treatment of craniopharyngiomas has been well recognized, 2 critical issues remain sources of significant controversy: 1) the merits of GTR versus subtotal resection followed by irradiation given the surgical morbidity and mortality rates associated with aggressive resection and 2) the role of RT immediately after resection without first monitoring for tumor progression and the role of RT in the absence of resection (up-front or salvage treatment).

On the basis of the complications associated with aggressive resection and the proven efficacy of radiation for craniopharyngiomas, several authors have recommended subtotal resection and RT as an acceptable alternative to total resection. Although clinicians can often mitigate the

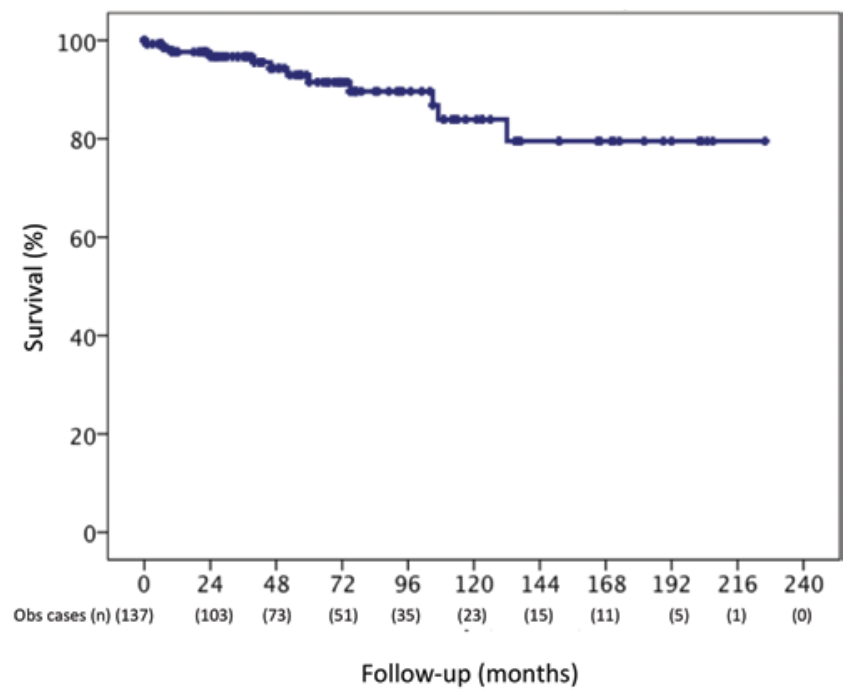

Fıg. 2. Kaplan-Meier overall survival curve for patients with a residual or recurrent craniopharyngioma after GKS. The survival rates were $91.5 \%$ and $83.9 \%$ at the 5 - and 10 -year follow-ups, respectively. 

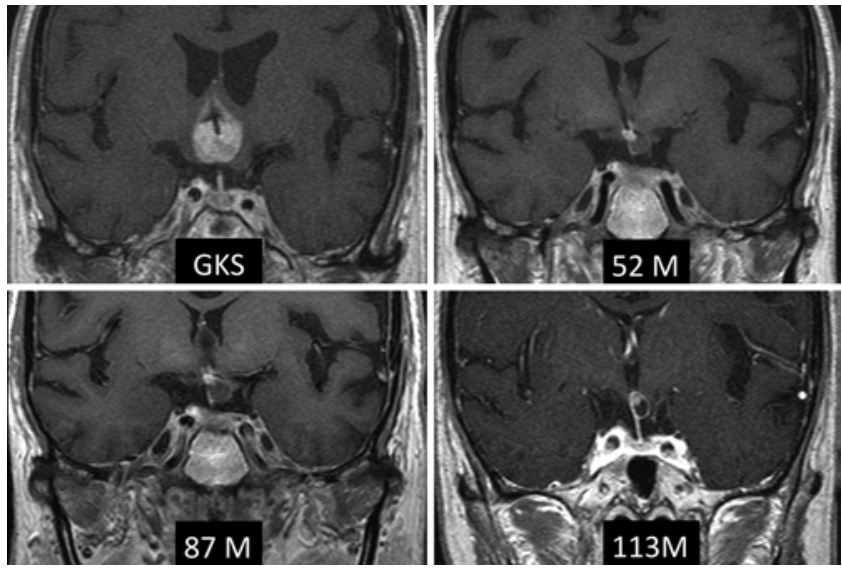

Fig. 3. A 55-year-old female patient had a cyst-type craniopharyngioma status post ventriculoperitoneal shunting and Ommaya reservoir implantation. She had bitemporal hemianopsia and hypopituitarism, and she underwent cyst aspirations several times before GKS. During the GKS, the cyst contents were aspirated, and then a 12-Gy radiation dose was delivered to the small enhanced nodule ( $0.6 \mathrm{ml}$ in volume) at the $54 \%$ isodose line. At 52, 87, and 113 months (M) after GKS, the tumor appeared as a tiny ill-defined suprasellar spot with mild enhancement. Her neuroendocrinological and ophthalmological statuses were stable at the last follow-up.

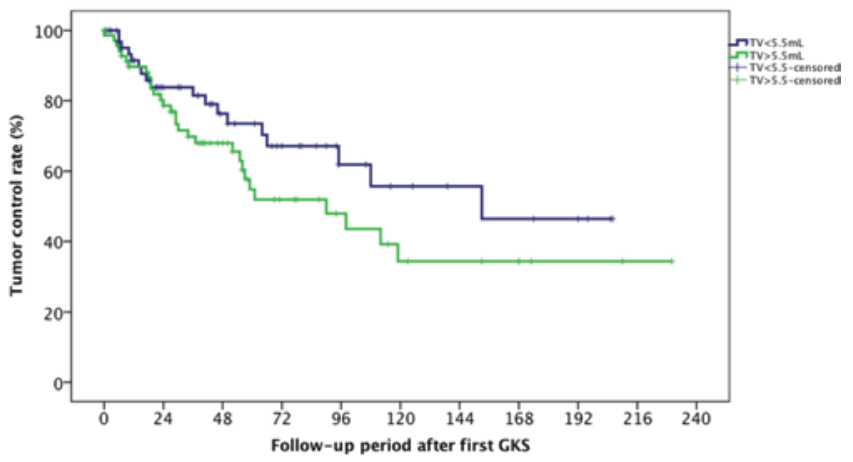

Fig. 5. Graph illustrating the influence of pre-GKS tumor volume (TV) on the tumor control rate of residual or recurrent craniopharyngiomas after GKS. The tumor control rate was better in the patients with a smaller tumor volume $(<5.5 \mathrm{ml})$; this difference was statistically significant $(p=0.011)$.

effects of neurological deficits and endocrinological dysfunction, the psychosocial consequences associated with radical resection are now recognized as the major limiting factors in quality of life as pediatric patients grow into adulthood. Thus, the minimization of surgical hypothalamic injury is crucial for optimizing the postoperative quality of life for patients with a craniopharyngioma,

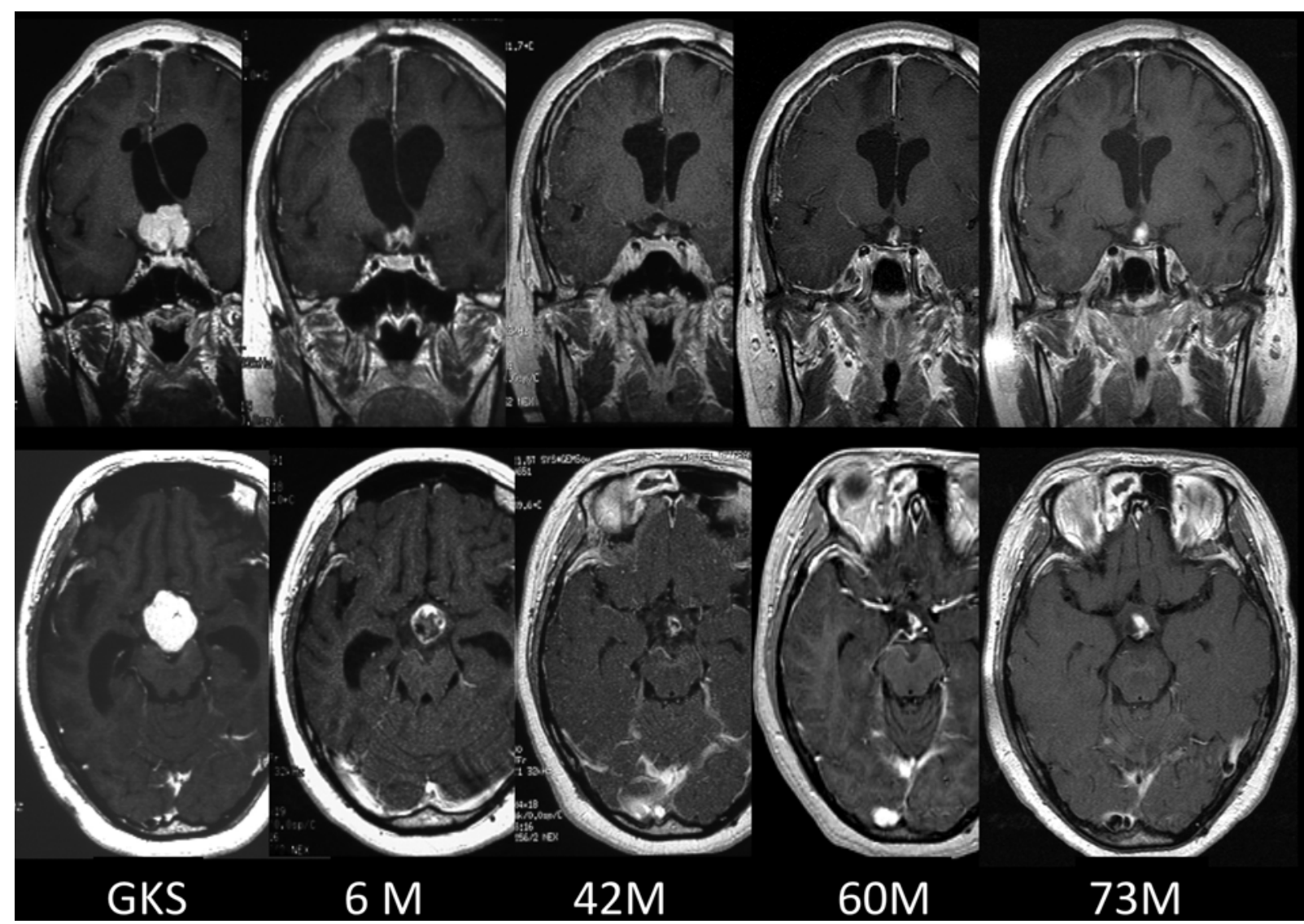

FIG. 4. A 21-year-old female patient had a solid-type craniopharyngioma status post craniotomy. Double vision, hypopituitarism, and diabetes insipidus were noted before GKS. Axial and coronal images revealed a 7.3-ml tumor. A 12-Gy dose was delivered to the tumor margin via 17 isocenters. On a follow-up series of images, the tumor was seen to be significantly decreased in volume. It appeared as a small enhanced spot, and no cyst was visualized. The patient's neuroendocrinological and ophthalmological statuses were stable at the last follow-up. 
TABLE 6: Prognostic factors of patients with a craniopharyngioma undergoing GKS

\begin{tabular}{|c|c|c|c|c|}
\hline \multirow[b]{2}{*}{ Factor } & \multicolumn{2}{|c|}{ Univariate Logistic Regression } & \multicolumn{2}{|c|}{ Multivariate Logistic Regression* } \\
\hline & p Value & OR $(95 \% \mathrm{Cl})$ & p Value & OR $(95 \% \mathrm{Cl})$ \\
\hline age (child vs adult) $\dagger$ & 0.582 & $0.816(0.395$ to $\sim 1.683)$ & - & - \\
\hline $\operatorname{sex}(F$ vs $M)$ & 0.555 & $0.805(0.392$ to 1.654$)$ & - & - \\
\hline margin dose (>12 vs $\leq 12$ Gy) & 0.450 & $1.687(0.435$ to $\sim 6.553)$ & - & - \\
\hline maximum dose (>21.8 vs $\leq 21.8 \mathrm{~Gy}$ ) & 0.719 & $0.871(0.411$ to $\sim 1.846)$ & - & - \\
\hline mean dose (>16 vs $\leq 16$ Gy) & 0.240 & $0.629(0.290$ to $\sim 1.364)$ & 0.779 & $1.010(0.943$ to $\sim 1.081)$ \\
\hline tumor vol ( $\leq 5.5 \mathrm{vs}>5.5 \mathrm{ml})$ & 0.050 & $2.042(0.996$ to $\sim 4.187)$ & 0.011 & 1.092 (1.021 to 1.168) \\
\hline \multicolumn{5}{|l|}{ tumor extension } \\
\hline suprasellar extension (yes vs no) & 0.453 & $0.622(0.179$ to $\sim 2.154)$ & - & - \\
\hline 3rd ventricle extension (yes vs no) & 0.847 & $0.913(0.359$ to $\sim 2.318)$ & - & - \\
\hline cavernous sinus (yes vs no) & 0.531 & $1.891(0.258$ to $~ 13.867)$ & - & - \\
\hline retrosellar extension (yes vs no) & 0.531 & $1.891(0.258$ to $~ 13.867)$ & - & - \\
\hline visual field deficits at GKS (yes vs no) & 0.312 & $2.272(0.463-11.153)$ & - & - \\
\hline pathology (adamantinomatous vs papillary) & 0.392 & 0.375 (0.04 to 3.551) & - & - \\
\hline resection (GTR vs biopsy or drainage only) & 0.119 & $1.827(0.857$ to $~ 3.896)$ & 0.251 & 1.585 (0.722 to $~ 3.479)$ \\
\hline
\end{tabular}

* The factors with a $p$ value of $<0.25$ in the univariate analysis were put in multivariate analysis.

$\dagger$ The cutoff value between a child and an adult was 18 years.

especially for younger patients. To limit significant neurological, endocrinological, and psychosocial morbidities that may accompany radical resection, some physicians prefer less aggressive resection followed by RT.

Some pediatric series have indicated that RT given immediately after surgery (up front) may be preferable to $\mathrm{RT}$ at the time of recurrence (salvage), with lower rates of morbidity and improved tumor control. ${ }^{12,31,36,43}$ However, for adult patients with a craniopharyngioma, there have been no significant differences in either tumor control or overall survival between up-front and salvage RT. ${ }^{10,29,35,42}$
Therefore, some clinicians advocate early postoperative RT or SRS for partially resected tumors. ${ }^{28}$

Because of the steep dose decrease with SRS compared with that with conventional RT, some physicians use SRS as a primary treatment for craniopharyngiomas. In a study of 5 pediatric patients with a craniopharyngioma in which SRS was the primary treatment for the solid portion of the mixed tumors after intracavitary phosphorus-32 was used to treat the cystic portion, 2 patients experienced tumor regression, and another 2 patients had tumor control. ${ }^{2}$ Other studies have shown higher tumor

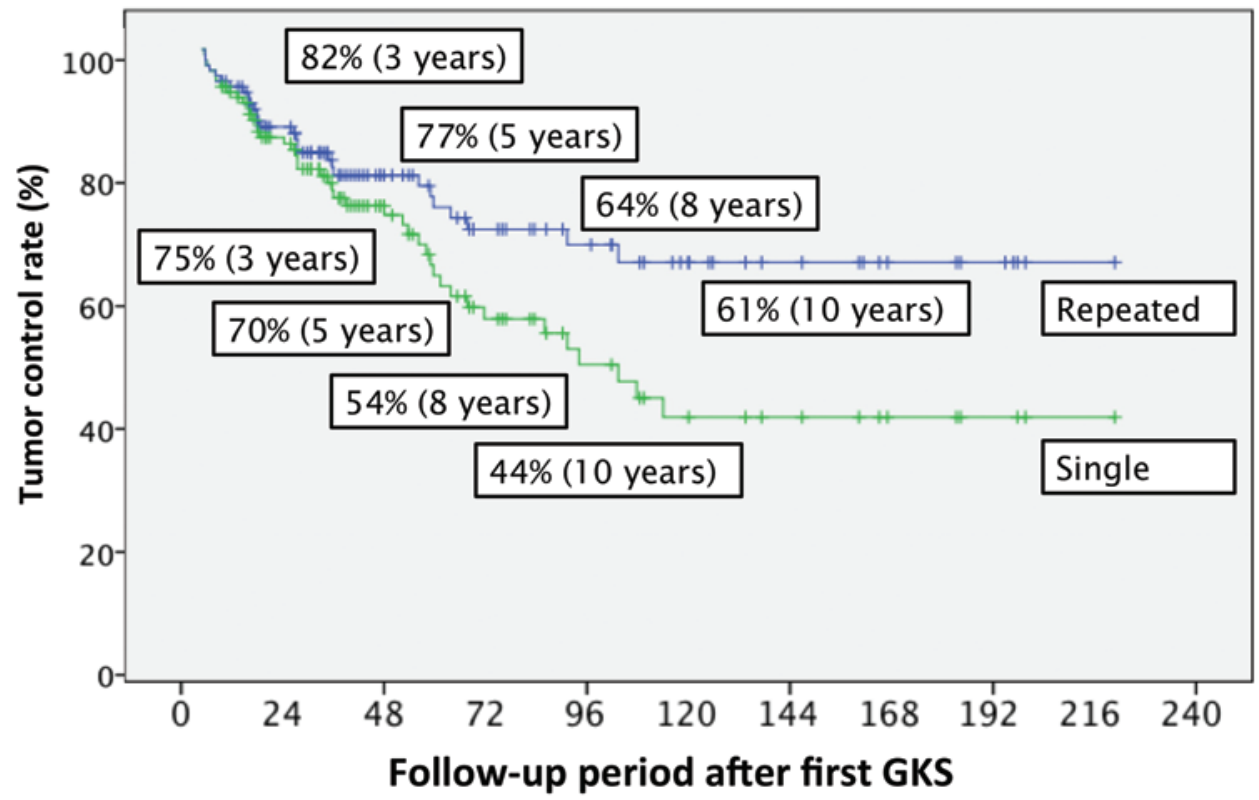

FIG. 6. Tumor control rates for repeated GKS for craniopharyngiomas. The lower green line demonstrates the tumor control rate via single GKS. The blue line shows the tumor control rate via repeated GKS when tumors were recurrent. With repeated GKS, the tumor control rates achieved were $7 \%, 7 \%, 10 \%$, and $17 \%$ higher at the 3-, 5-, 8-, and 10 -year follow-ups, respectively. 
TABLE 7: Clinical outcomes of the patients who underwent regular follow-up after GKS for a craniopharyngioma*

\begin{tabular}{|c|c|c|c|c|}
\hline Clinical Parameter (no.)† & Improvement (no.) & Stability (no.) & Deterioration (no.) & Not Available (no.) \\
\hline \multicolumn{5}{|l|}{ visual field } \\
\hline pre-GKS normal (10) & - & 10 & 0 & 0 \\
\hline pre-GKS deficits (127) & 13 & 77 & 28 (2 w/o tumor growth) & 9 \\
\hline \multicolumn{5}{|l|}{ hypopituitarism } \\
\hline pre-GKS normal (19) & - & 17 & 1 & 0 \\
\hline pre-GKS deficits (118) & 0 & 99 & 10 & 9 \\
\hline \multicolumn{5}{|l|}{ cranial nerve function } \\
\hline pre-GKS normal (127) & - & 111 & 7 (1 w/o tumor growth) & 9 \\
\hline pre-GKS deficits (10) & 1 & 9 & 0 & 0 \\
\hline \multicolumn{5}{|l|}{ diabetes insipidus } \\
\hline pre-GKS normal (52) & - & 48 & 1 (w/o tumor growth) & 3 \\
\hline pre-GKS deficits (85) & 3 & 76 & 0 & 6 \\
\hline
\end{tabular}

control rates in single-type tumors (solid or cystic) compared with that in mixed-type tumors. Chung et al. ${ }^{8}$ found that single-type tumors were more responsive to primary radiosurgical treatment in contrast to mixed-type tumors. It is also believed that solid-type tumors and the solid portions of mixed-type tumors are less responsive to intracavitary irradiation than are cystic tumors. ${ }^{19,20}$ As a result, Prasad et al. ${ }^{34}$ recommended that mixed-type tumors be treated with a combination of radioisotope instillation and SRS. The combination of SRS and intracavitary radiation has been advocated as a primary treatment for mixed cystic-solid tumors. ${ }^{2,47}$

\section{Study Limitations}

The current study was retrospective in nature. Inherent to this study design, there exist patient selection and treat-

\section{TABLE 8: Complications of GKS in patients with a craniopharyngioma*}

\begin{tabular}{lcc}
\hline \multicolumn{1}{c}{ Complication } & No. of Cases & Ratio $(\%)$ \\
\hline adverse radiation effects & 2 & 1.5 \\
visual deterioration & 2 & 1.5 \\
new CN palsy & $1 \dagger$ & 0.7 \\
cerebrovascular accident & 0 & 0 \\
secondary tumor & 0 & 0 \\
hypopituitarism & 11 & 8.0 \\
hypothyroidism & 8 & \\
hypoadrenalism & 8 & \\
hyposomatotropism & 4 & \\
hypogonadism & 2 & \\
panhypopituitarism & 2 & 10.9 \\
total & 15 & \\
\hline
\end{tabular}

* The complications were found in 137 patients who underwent regular clinical follow-up.

$\dagger$ The patient with new-onset third cranial nerve palsy also had visual deterioration simultaneously. ment biases reflective of the treating clinicians and institution. Selection bias may have been present in this study, because the majority of patients did not achieve GTR, which may indicate cases of higher complexity. In addition, the decisions of whether to use GKS or RT were not made by using a stringent guideline because these decisions were often made at the discretion of the treating physicians.

\section{Conclusions}

The messages we deliver from this report are the following: 1) the overall survival rates for patients after GKS performed to treat a residual or recurrent craniopharyngioma were $91.5 \%$ and $83.9 \%$ at the 5- and 10-year followups, respectively; 2) the progression-free survival rates for patients after GKS for a residual or recurrent craniopharyngioma were $70.0 \%$ and $43.8 \%$ at the 5 - and 10 -year follow-ups, respectively; 3) a smaller tumor volume was associated with successful treatment with GKS; and 4) complications included hypopituitarism $(8.0 \%)$, adverse radiation effects $(1.5 \%)$, visual deterioration $(1.5 \%)$, and new-onset cranial nerve palsy $(0.7 \%)$.

The results of our study suggest that GKS is a relatively safe modality for the treatment of recurrent or residual craniopharyngiomas and is associated with improved tumor control and in-field progression-free survival rates. Acceptable rates of complications were observed.

\section{Disclosure}

The authors report no conflict of interest concerning the materials or methods used in this study or the findings specified in this paper.

Author contributions to the study and manuscript preparation include the following. Conception and design: Liu, Lee, Yang, Hung, Chung, Pan. Acquisition of data: Lee, Yang, Hung, Pan. Analysis and interpretation of data: Liu, Lee, Yang, Chen. Drafting the article: Lee, Chen, Hung. Critically revising the article: Liu, Lee, Yang, Chen, Chung. Reviewed submitted version of manuscript: Liu, Lee, Yang, Chen, Guo, Chung. Approved the final version of the manuscript on behalf of all authors: Liu. Statistical analysis: Lee, 
C. C. Lee et al.

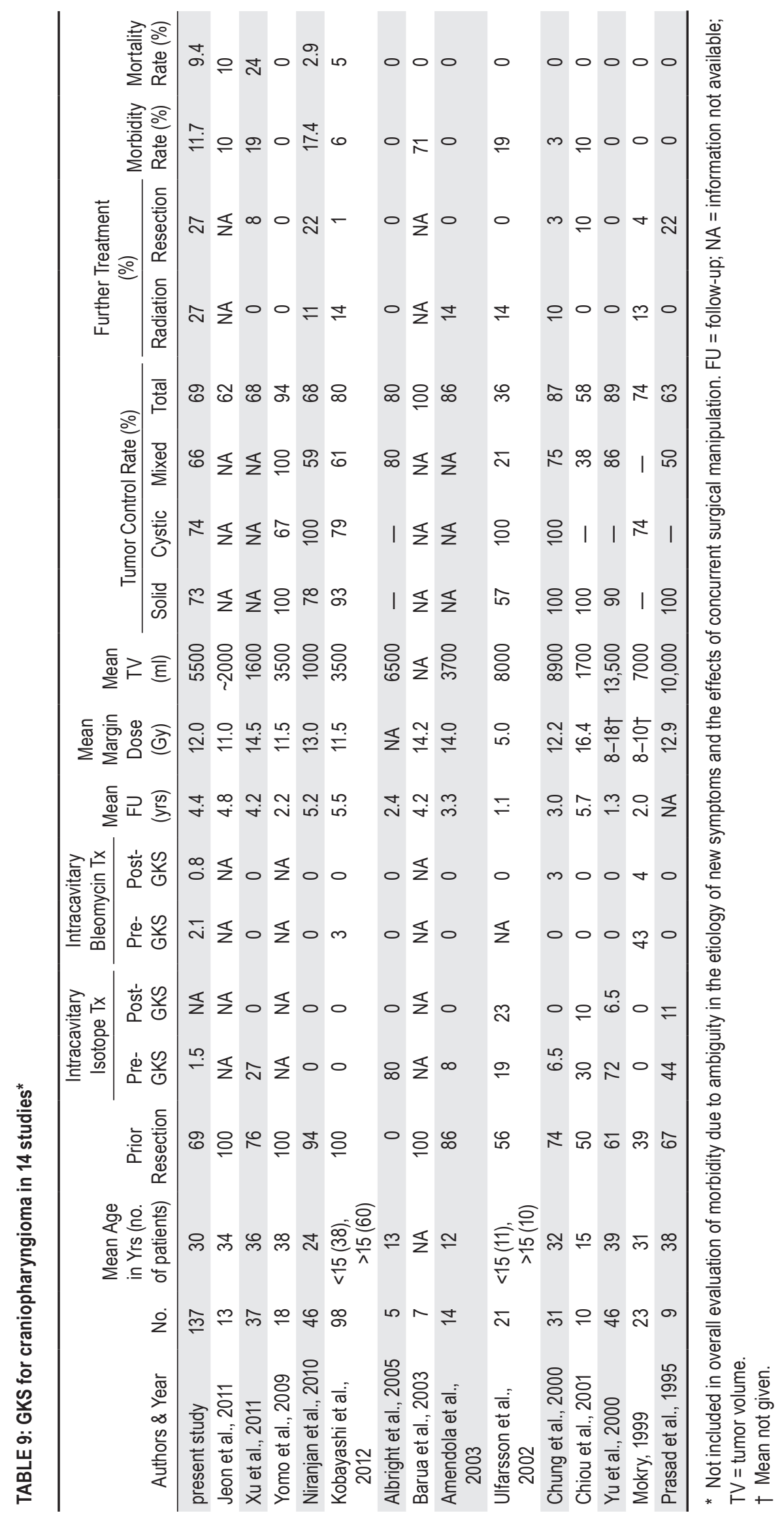


Yang, Chen, Hung. Administrative/technical/material support: Liu, $\mathrm{Wu}$, Shiau, Guo, Chung, Pan. Study supervision: Liu, Wu, Guo, Chung, Pan.

\section{References}

1. Adler JR Jr, Gibbs IC, Puataweepong P, Chang SD: Visual field preservation after multisession cyberknife radiosurgery for perioptic lesions. Neurosurgery 59:244-254, 2006

2. Albright AL, Hadjipanayis CG, Lunsford LD, Kondziolka D, Pollack IF, Adelson PD: Individualized treatment of pediatric craniopharyngiomas. Childs Nerv Syst 21:649-654, 2005

3. Amendola BE, Wolf A, Coy SR, Amendola MA: Role of radiosurgery in craniopharyngiomas: a preliminary report. Med Pediatr Oncol 41:123-127, 2003

4. Barua KK, Ehara K, Kohmura E, Tamaki N: Treatment of recurrent craniopharyngiomas. Kobe J Med Sci 49:123-132, 2003

5. Campbell PG, McGettigan B, Luginbuhl A, Yadla S, Rosen M, Evans JJ: Endocrinological and ophthalmological consequences of an initial endonasal endoscopic approach for resection of craniopharyngiomas. Neurosurg Focus 28(4):E8, 2010

6. Chakrabarti I, Amar AP, Couldwell W, Weiss MH: Longterm neurological, visual, and endocrine outcomes following transnasal resection of craniopharyngioma. J Neurosurg 102:650-657, 2005

7. Chiou SM, Lunsford LD, Niranjan A, Kondziolka D, Flickinger JC: Stereotactic radiosurgery of residual or recurrent craniopharyngioma, after surgery, with or without radiation therapy. Neuro Oncol 3:159-166, 2001

8. Chung WY, Pan DH, Shiau CY, Guo WY, Wang LW: Gamma knife radiosurgery for craniopharyngiomas. J Neurosurg 93 (Suppl 3):47-56, 2000

9. Chung WY, Pan HC, Guo WY, Shiau CY, Wang LW, Wu HM, et al: Protection of visual pathway in gamma knife radiosurgery for craniopharyngiomas. Stereotact Funct Neurosurg 70 (Suppl 1):139-151, 1998

10. Combs SE, Thilmann C, Huber PE, Hoess A, Debus J, SchulzErtner D: Achievement of long-term local control in patients with craniopharyngiomas using high precision stereotactic radiotherapy. Cancer 109:2308-2314, 2007

11. Fahlbusch R, Honegger J, Paulus W, Huk W, Buchfelder M: Surgical treatment of craniopharyngiomas: experience with 168 patients. J Neurosurg 90:237-250, 1999

12. Habrand JL, Ganry O, Couanet D, Rouxel V, Levy-Piedbois $\mathrm{C}$, Pierre-Kahn A, et al: The role of radiation therapy in the management of craniopharyngioma: a 25-year experience and review of the literature. Int J Radiat Oncol Biol Phys 44:255263, 1999

13. Hasegawa T, Kobayashi T, Kida Y: Tolerance of the optic apparatus in single-fraction irradiation using stereotactic radiosurgery: evaluation in 100 patients with craniopharyngioma. Neurosurgery 66:688-695, 2010

14. Higuchi F, Kawamoto S, Abe Y, Kim P, Ueki K: Effectiveness of a 1-day aspiration plus Gamma Knife surgery procedure for metastatic brain tumor with a cystic component. Clinical article. J Neurosurg 117 Suppl:17-22, 2012

15. Hoffman HJ, De Silva M, Humphreys RP, Drake JM, Smith ML, Blaser SI: Aggressive surgical management of craniopharyngiomas in children. J Neurosurg 76:47-52, 1992

16. Honegger J, Buchfelder M, Fahlbusch R: Surgical treatment of craniopharyngiomas: endocrinological results. J Neurosurg 90:251-257, 1999

17. Jang WY, Lee KS, Son BC, Jeun SS, Hong YK, Lee SW, et al: Repeat operations in pediatric patients with recurrent craniopharyngiomas. Pediatr Neurosurg 45:451-455, 2009

18. Jeon C, Kim S, Shin HJ, Nam DH, Lee JI, Park K, et al: The therapeutic efficacy of fractionated radiotherapy and gamma- knife radiosurgery for craniopharyngiomas. J Clin Neurosci 18:1621-1625, 2011

19. Julow J, Backlund EO, Lányi F, Hajda M, Bálint K, Nyáry I, et al: Long-term results and late complications after intracavitary yttrium-90 colloid irradiation of recurrent cystic craniopharyngiomas. Neurosurgery 61:288-296, 2007

20. Julow J, Lányi F, Hajda M, Szeifert GT, Viola A, Bálint K, et al: Stereotactic intracavitary irradiation of cystic craniopharyngiomas with yttrium-90 isotope. Prog Neurol Surg 20: 289-296, 2007

21. Karavitaki N, Wass JA: Craniopharyngiomas. Endocrinol Metab Clin North Am 37:173-193, ix-x, 2008

22. Kobayashi T, Kida Y, Mori Y, Hasegawa T: Long-term results of gamma knife surgery for the treatment of craniopharyngioma in 98 consecutive cases. J Neurosurg 103 (6 Suppl): 482-488, 2005

23. Kobayashi T, Mori Y, Tsugawa T, Hashizume C, Takahashi $\mathrm{H}$ : Prognostic factors for tumor recurrence after gamma knife radiosurgery of partially resected and recurrent craniopharyngiomas. Nagoya J Med Sci 74:141-147, 2012

24. Komotar RJ, Roguski M, Bruce JN: Surgical management of craniopharyngiomas. J Neurooncol 92:283-296, 2009

25. Lindholm J, Nielsen EH: Craniopharyngioma: historical notes. Pituitary 12:352-359, 2009

26. Liu X, Yu Q, Zhang Z, Zhang Y, Li Y, Liu D, et al: Sameday stereotactic aspiration and Gamma Knife surgery for cystic intracranial tumors. Clinical article. J Neurosurg 117 Suppl:45-48, 2012

27. Minamida Y, Mikami T, Hashi K, Houkin K: Surgical management of the recurrence and regrowth of craniopharyngiomas. J Neurosurg 103:224-232, 2005

28. Minniti G, Esposito V, Amichetti M, Enrici RM: The role of fractionated radiotherapy and radiosurgery in the management of patients with craniopharyngioma. Neurosurg Rev 32:125132,2009

29. Minniti G, Saran F, Traish D, Soomal R, Sardell S, Gonsalves A, et al: Fractionated stereotactic conformal radiotherapy following conservative surgery in the control of craniopharyngiomas. Radiother Oncol 82:90-95, 2007

30. Mokry M: Craniopharyngiomas: a six year experience with Gamma Knife radiosurgery. Stereotact Funct Neurosurg 72 (Suppl 1):140-149, 1999

31. Moon SH, Kim IH, Park SW, Kim I, Hong S, Park CI, et al: Early adjuvant radiotherapy toward long-term survival and better quality of life for craniopharyngiomas - a study in single institute. Childs Nerv Syst 21:799-807, 2005

32. Niranjan A, Kano H, Mathieu D, Kondziolka D, Flickinger JC, Lunsford LD: Radiosurgery for craniopharyngioma. Int J Radiat Oncol Biol Phys 78:64-71, 2010

33. Park KJ, Niranjan A, Kondziolka D, Kano H, Castillo P, Matchett JC, et al: Combining brain diagnosis and therapy in a single strategy: the safety, reliability, and cost implications using same-day versus separate-day stereotactic procedures. Stereotact Funct Neurosurg 89:346-356, 2011

34. Prasad D, Steiner M, Steiner L: Gamma knife surgery for craniopharyngioma. Acta Neurochir (Wien) 134:167-176, 1995

35. Rajan B, Ashley S, Gorman C, Jose CC, Horwich A, Bloom $\mathrm{HJ}$, et al: Craniopharyngioma-a long-term results following limited surgery and radiotherapy. Radiother Oncol 26:1-10, 1993

36. Regine WF, Mohiuddin M, Kramer S: Long-term results of pediatric and adult craniopharyngiomas treated with combined surgery and radiation. Radiother Oncol 27:13-21, 1993

37. ShiXE,Wu B,Fan T,ZhouZQ,Zhang YL: Craniopharyngioma: surgical experience of 309 cases in China. Clin Neurol Neurosurg 110:151-159, 2008

38. Shirane R, Ching-Chan S, Kusaka Y, Jokura H, Yoshimoto T: Surgical outcomes in 31 patients with craniopharyngiomas extending outside the suprasellar cistern: an evaluation 
of the frontobasal interhemispheric approach. J Neurosurg 96:704-712, 2002

39. Snell JW, Sheehan J, Stroila M, Steiner L: Assessment of imaging studies used with radiosurgery: a volumetric algorithm and an estimation of its error. Technical note. J Neurosurg 104:157-162, 2006

40. Ulfarsson E, Lindquist C, Roberts M, Rähn T, Lindquist M, Thorén M, et al: Gamma knife radiosurgery for craniopharyngiomas: long-term results in the first Swedish patients. J Neurosurg 97 (5 Suppl):613-622, 2002

41. Van Effenterre R, Boch AL: Craniopharyngioma in adults and children: a study of 122 surgical cases. J Neurosurg 97:3-11, 2002

42. Varlotto JM, Flickinger JC, Kondziolka D, Lunsford LD, Deutsch M: External beam irradiation of craniopharyngiomas: long-term analysis of tumor control and morbidity. Int $\mathbf{J}$ Radiat Oncol Biol Phys 54:492-499, 2002

43. Weiss M, Sutton L, Marcial V, Fowble B, Packer R, Zimmerman $\mathrm{R}$, et al: The role of radiation therapy in the management of childhood craniopharyngioma. Int J Radiat Oncol Biol Phys 17:1313-1321, 1989

44. Xu Z, Yen CP, Schlesinger D, Sheehan J: Outcomes of Gamma Knife surgery for craniopharyngiomas. J Neurooncol 104: 305-313, 2011
45. Yaşargil MG, Curcic M, Kis M, Siegenthaler G, Teddy PJ, Roth P: Total removal of craniopharyngiomas. Approaches and long-term results in 144 patients. J Neurosurg 73:3-11, 1990

46. Yomo S, Hayashi M, Chernov M, Tamura N, Izawa M, Okada $\mathrm{Y}$, et al: Stereotactic radiosurgery of residual or recurrent craniopharyngioma: new treatment concept using Leksell gamma knife model $\mathrm{C}$ with automatic positioning system. Stereotact Funct Neurosurg 87:360-367, 2009

47. Yu X, Liu Z, Li S: Combined treatment with stereotactic intracavitary irradiation and gamma knife surgery for craniopharyngiomas. Stereotact Funct Neurosurg 75:117-122, 2000

48. Zuccaro G: Radical resection of craniopharyngioma. Childs Nerv Syst 21:679-690, 2005

Manuscript submitted June 30, 2014.

Accepted August 11, 2014.

Please include this information when citing this paper: DOI: 10.3171/2014.8.GKS141411.

Address correspondence to: Kang-Du Liu, M.D., Department of Neurosurgery, Neurological Institute, Taipei Veterans General Hospital, 17F, No. 201, Shih-Pai Rd., Sec. 2, Peitou, Taipei 11217 , Taiwan, ROC.email: kdliou@vghtpe.gov.tw. 